\title{
Modeling feeding and growth in Gulf of Alaska sockeye salmon: implications for high-seas distribution and migration
}

\author{
Peter S. Rand* \\ Department of Zoology, North Carolina State University, Raleigh, North Carolina 27695-7617, USA
}

\begin{abstract}
I analyzed data on stomach contents of sockeye salmon Oncorhynchus nerka and oceanographic variables collected during 1956 to 1964 in order to assess the spatial and temporal patterns of salmon feeding and growth in the Gulf of Alaska. A 2-stage statistical model was used to develop a feeding index, calculated as the product of feeding probability (assessed using the presence/absence of gut contents of individuals collected at each site) and stomach fullness (prey weights transformed to account for temperature-dependent gastric evacuation and allometry). Combining these results with simple bioenergetic principles, I conclude that the reduction in salmon biomass during spring observed along the southern periphery of the Gulf can be explained by an equally sharp reduction in growth potential. This feature demarcates a region (between latitude 58 and $55^{\circ} \mathrm{N}$ ) that is favorable to sockeye growth, as demonstrated by an order of magnitude change in salmon growth potential over a narrow range of sea surface temperatures (ca. 6 to $7^{\circ} \mathrm{C}$ ). This pattern results from the combined effects of trends in feeding probability and stomach fullness across this temperature gradient. I documented a significant trend of larger fish in cooler water during spring, which might have been related to body size dependent competitive interactions. The trend was reversed in summer, with larger fish in warmer water, perhaps due to the availability of preferred prey (e.g. squid) and directional swimming behavior characteristic of sockeye spawning migration. Assuming salmon are growth-optimizers in this environment, my results suggest that winter residency for sub-adults is restricted to north of latitude $54^{\circ} \mathrm{N}$. Furthermore, peaks in feeding and growth shifted from a central position in the gulf during spring toward the southeast during summer, with an attendant increase in forage quality. I hypothesize that these patterns are likely to be important in drawing maturing British Columbia salmon toward their natal rivers and providing the energy needed to fuel their costly river migration during mid-summer.
\end{abstract}

KEY WORDS: Sockeye salmon · Gulf of Alaska · Bioenergetics · Growth · Foraging · Habitat selection · Migration

\section{INTRODUCTION}

While the general patterns of distribution and migration of Pacific salmon in marine environments have already been documented, we still lack a clear understanding of these patterns from an ecological perspective. We now know that salmon are not distributed uni-

*E-mail: pete_rand@ncsu.edu formly in the subarctic Pacific Ocean (e.g. McKinnell 1995, Welch et al. 1995, 1998, Nero \& Huster 1996). Furthermore, we know that planktonic prey distribution and the dietary habits of salmon are dynamic in space and time (e.g. LeBrasseur 1966, Pearcy et al. 1984, 1988, Manzer 1986, Brodeur \& Ware 1992, 1995, Rand \& Hinch 1998). While various models have been developed to explore migration and bioenergetic processes of salmon on the high seas (e.g. Hinch et al. 1995a,b, Rand et al. 1997, Walter et al. 1997), these 
models are critically deficient in mechanistic details related to foraging. While many data exist on patterns of spatial distribution and diet composition of marine salmon, I contend that there has been very little emphasis on using these data to construct models to help advance our understanding of how migration and habitat selection can be perceived as an adaptive strategy (Healey 2000, Rand 2000). It is in this spirit that I present a hypothesis involving habitat selection by marine salmon based on an extensive oceanographic data set on salmon dietary habits and environmental variables.

Many factors have been identified as important in influencing the distribution and migration patterns of marine salmon, including sea surface temperature, currents, different biological properties of water masses, and salmon feeding and migration behavior (cf. Burgner 1991). However, it remains unclear how these factors interact to influence habitat quality for salmon in this environment. Welch et al. (1995) advanced a hypothesis to explain how sea surface temperatures serve to limit the southern distribution of salmon in the Northeast Pacific. Welch et al. (1998) used this relationship to project the potential impact of global climate change on the marine habitat for Pacific salmon. These authors concluded that the most likely explanation for the observed distribution patterns is a direct behavioral avoidance of temperatures exceeding some critical threshold. An alternative hypothesis is that salmon are distributed in the Gulf in a manner that maximizes individual rates of growth. In this case, salmon are expected to adopt behaviors (specifically migratory and foraging behaviors) that would tend to maximize growth rate and, ultimately, fitness (cf. Houston et al. 1988). This growth-maximization hypothesis was discounted by Welch et al. (1998) on the premise that growth rate could not show such a strong functional response over such a narrow temperature range. However, one must consider the potential interaction between temperature and ecological processes that may influence feeding performance. Feeding and ultimately growth may be strongly influenced by frontal zones in marine ecosystems (cf. Mann \& Lazier 1991, Brandt 1993). Amna et al. (1990) documented a marked reduction in chlorophyll south of latitude $48^{\circ} \mathrm{N}$ along a transect at Longitude $180^{\circ} \mathrm{W}$, suggesting the existence of such a frontal feature. LeBrasseur (1966) and Pearcy et al. (1988) both document a boundary between latitude 50 and $54^{\circ} \mathrm{N}$ that separates high zooplankton densities (north) and elevated squid abundance (south) as reflected in salmon dietary data. This latitude is above the boundary of the Transition Zone in the North Pacific and corresponds closely with the southern limit of sockeye salmon as described by Welch et al. (1995). It is likely that temperature and salmon food availability covary along this latitudinal gradient. Salmon distributed along this frontal feature are likely to experience different foraging opportunities and metabolic demands. This could have implications on salmon distribution and migration behavior on the high-seas.

I investigate this growth-maximization hypothesis by conducting an analysis of stomach contents of sockeye salmon collected throughout the Gulf of Alaska. I set out to accomplish several objectives in this paper: (1) To determine factors that help explain variability in feeding probability and degree of stomach fullness in sockeye salmon in the Gulf of Alaska by fitting statistical models to dietary data; (2) to compute feeding and growth indices based on the best-fit statistical models and bioenergetic principles to explain important temporal and spatial patterns in habitat quality; (3) to draw inferences on how these patterns may influence the distribution and migration behavior of salmon during their marine life history. In this paper I advance an alternative hypothesis of growth optimization that can explain the sharp thermal limits during spring reported by Welch et al. $(1995,1998)$. Furthermore, I extend this hypothesis to document potentially important shifts in the habitat quality of salmon during winter and summer that have implications for understanding adaptive migration strategies in Pacific salmon.

\section{MATERIALS AND METHODS}

Stomach contents and sea surface temperature. I summarized patterns observed in stomach contents of Oncorhynchus nerka and sea surface temperature within the Gulf of Alaska during 1956 to 1964. These data were available from the Department of Fisheries and Oceans, Pacific Biological Station at Nanaimo, British Columbia (LeBrasseur 1965). The sampling was extensive in space (latitude 46 to $60^{\circ} \mathrm{N}$, longitude 125 to $160^{\circ} \mathrm{W}$ ) and time (1956 to 1964 , winter, spring and summer over a diel cycle). Salmon for the diet survey were collected using gill nets. The catches were quick frozen on board and held in cold storage boxes for later examination in the laboratory. The weight of the salmon was determined to the nearest $10 \mathrm{~g}$. I restricted the analysis to salmon larger than $500 \mathrm{~g}$; this cutoff was chosen in order to focus the analysis on subadult salmon that had migrated to offshore waters. The weight of the stomach contents was determined to the nearest $0.1 \mathrm{~g}$ by weighing the intact stomach (from esophagus to pyloric sphincter), removing the contents, and reweighing the empty stomach. The difference in these 2 weights represented the weight of the stomach contents. Additional details of the sampling protocol can be found in LeBrasseur $(1965,1966)$. 
Statistical model and response variables. I applied a statistical approach involving 2 separate models; a similar approach is described in Stefansson \& Palsson (1997) and Maravelias (1999). The first model considered stomachs as either empty or nonempty (assigning values of 0 or 1, respectively) and I assumed a binomial error distribution (response variable $\mathrm{PF}=$ probability of feeding, hereafter referred to as the 'probability of feeding model'). For the second model, I considered only nonempty stomachs. The response variable in this case was a measure of stomach fullness $(P=$ percentage of a daily maximum rate predicted under laboratory conditions) to reflect recent feeding history in the field (hereafter referred to as the stomach fullness model). For this latter model, I assumed a Gaussian error distribution. I used 3 different transformations of the response variable. I used an exponential model to correct for the temperature dependence of gastric evacuation rate, an allometric relationship for maximum consumption rate to account for body size, and a log transformation to normalize the data. The computation is as follows:

$$
P=\log \left\{\left(\mathrm{SWe}^{\gamma \mathrm{SST}}\right) / \alpha \mathrm{BW}^{\beta}\right\}
$$

where SW = raw wet weight of stomach contents in $\mathrm{g}$, $\gamma=a$ temperature dependent gastric evacuation rate parameter (0.114, from Elliot 1991), SST = sea surface temperature $\left({ }^{\circ} \mathrm{C}\right), \mathrm{BW}=$ body weight of salmon in grams, $\alpha=$ intercept of weight-dependent maximum consumption rate $(0.303$, from Beauchamp et al. 1989), and $\beta=$ allometric coefficient for maximum consumption $(0.72$, from Beauchamp et al. 1989). I chose to use the results of Elliot (1991) for the evacuation rate parameter because his study presents the most exhaustive set of evacuation experiments conducted on a salmonid. The parameter chosen reflects a mixed natural diet of invertebrates and fishes, which closely resembles that of sockeye. The prediction of Elliot's model at $10^{\circ} \mathrm{C}$ compares favorably with the rate measured during ship-board experiments conducted on long-line caught pink salmon Oncorhynchus gorbuscha (Hiramatsu et al. 1996).

Under the assumption that the form of the relationships between the response variables and the explanatory variables in this analysis would probably be nonlinear, I fit the data to a generalized additive model (GAM) of the form:

$$
\begin{gathered}
\mathrm{PF}=\mu+s(\mathrm{SST})+s(\mathrm{WT})+s(\mathrm{LAT})+ \\
s(\mathrm{LNG})+s(\mathrm{YR})+s(\mathrm{DOY})+\mathrm{TOD} \\
(\text { probability of feeding model })
\end{gathered}
$$

or:

$$
\begin{gathered}
P=\mu+s(\mathrm{SST})+s(\mathrm{WT})+s(\mathrm{LAT})+ \\
s(\mathrm{LNG})+s(\mathrm{YR})+s(\mathrm{DOY})+\mathrm{TOD}
\end{gathered}
$$

(stomach fullness model) where $\mathrm{PF}=$ probability of a stomach containing prey items ( 0 or 1 , as described above), $\mu=$ mean response, $\mathrm{WT}=$ total weight of salmon $(\mathrm{g}), \mathrm{LAT}=$ degrees north latitude, $\mathrm{LNG}=$ degrees west longitude, $\mathrm{YR}=$ year of sampling, DOY = day of year, and TOD = time of day, a categorical variable reflecting when the sampling took place $(\mathrm{DN}=$ dawn, $\mathrm{DY}=$ day, $\mathrm{NT}=$ night , or some combination thereof). The ' $s$ ' term in the model refers to a spline smoother applied with $3 \mathrm{df}$. I included the year of data collection in the analysis to account for interannual variability in the response variables. I include a description of the effect of year in the 'Results' section, but it is beyond the scope of this paper to draw conclusions regarding inter-annual variation in feeding and growth measures. I applied the GAM to the entire data set, i.e. all salmon were analyzed in the probability of feeding model, and all salmon containing prey items were included in the analysis using the stomach fullness model. I then fit the GAM to subsets of the data set for which there were sufficient samples to describe seasonal spatial patterns. Data from 2 winter cruises were combined (January and February 1963 and 1964). I analyzed dietary data for spring periods (April and May 1962 and 1963) and a summer period (June and August 1962).

I computed an Akaike Information Criterion (AIC) statistic to determine an appropriate form of the model. I considered both linear and nonlinear representations of the effect of the explanatory variables on the response variables (Eq. 2). I stepped through alternative forms of the model (3 different permutations: variable included or removed, variable effect assumed linear, variable effect assumed nonlinear) and selected the model that resulted in the greatest decrease in the AIC using the stepgam procedure in S-Plus 2000 (Insightful Corporation), computed as follows:

$$
\mathrm{AIC}=D+2 \mathrm{df} \phi
$$

where $D=$ residual deviance, $\mathrm{df}=$ effective degrees of freedom used in fitting the model, and $\phi$ is the dispersion parameter residual sum of squares divided by residual degrees of freedom.

I provide estimates of the contribution of each predictor to the overall model fit using a $t$-ratio statistical inference (similar to the approach in generalized linear models) and an estimate of the nonlinear effect for each of the continuous explanatory variables using a nonparametric F-ratio test statistic. Further details of this statistical approach can be found in Hastie \& Tibshirani (1990). These analyses were conducted using S-Plus 2000.

Feeding and growth indices. Using the most appropriate form of the statistical model derived above, I modeled probabilities of feeding and degree of stomach fullness over time (winter, spring and summer) and 
space (latitude 48 to $60^{\circ} \mathrm{N}$, longitude 125 to $160^{\circ} \mathrm{W}$ ) using values of independent variables that were found to be significant in the GAM (SST, WT, LAT, LNG, DOY, TOD, defined above for Eq. 2). I focused the analysis for the spring period on data collected during 1963 based on more extensive sample coverage. To help confirm that results from this data set can be generalized, I repeated the analysis for spring 1962 to determine if the same spatial patterns were evident. I first selected grid points (latitude and longitude coordinates) within a convex hull around the salmon diet sampling stations for each seasonal period. I then used the GAM (with latitude and longitude as covariates) to interpolate values of SST and mean sockeye body size onto this spatial grid for each data set. These gridded variables were used to predict feeding probability and stomach fullness using the reduced form of the GAM described above (Eq. 2). I normalized the stomach fullness predictions across the grid by assigning a value of unity to the maximum stomach fullness prediction and proportionally scaling the remaining values. I then computed an integrated feeding index based on these response variables from the GAM. The feeding index (FI) was derived by taking the product of the 2 response variables identified above $(\mathrm{FI}=\mathrm{PF} \times P$, scaled from 0 to 1). Thus, this index represents a normalized instantaneous measure of consumed prey expressed as a proportion of maximum daily consumption rate conditioned on the probability of observing fish actively engaged in feeding.

The resulting values of FI were used to compute a growth rate index $($ GRI $=$ FI $\times$ CMAX-LOSSES, where CMAX = maximum daily consumption rate ( $g$ per $g$ body wt $\mathrm{d}^{-1}$ ) and LOSSES = daily losses due to egestion, excretion and metabolism). This metric is similar to the 'growth rate potential' espoused by Brandt et al. (1992), but in the present context the terms that limit consumption in the energy balance equation were derived in a more empirical way based on data drawn from the diet survey. I accounted for bioenergetic losses based on an existing model of sockeye salmon (Beauchamp et al. 1989). Although I refer in the paper to measures of feeding and growth, it should be recognized that the resulting predictions

Table 1. Oncorhynchus nerka. Summary of parameter estimates to be applied to explanatory variables and statistical tests for generalized additive model (GAM) on sockeye salmon dietary data (pooled over prey types and seasons). Probability of feeding model: null deviance $=4525.6$ on $3483 \mathrm{df}$, residual deviance $=3956.14$ on $3458 \mathrm{df}$, quasi-likelihood dispersion parameter $=1$, $\mathrm{R}^{2}=(4525.6-3956.1) / 4525.6=0.13$; stomach fullness model: null deviance $=4061.1$ on $2252 \mathrm{df}$, residual deviance $=3432.5$ on 2226 df, quasi-likelihood dispersion parameter $=1.542, \mathrm{R}^{2}=(4061.1-3432.5) / 4061.1=0.16$. SST: sea surface temperature; DOY: day of year; TOD: time of day; DN: dawn; DY: day; NT: night; ns: not significant

\begin{tabular}{|c|c|c|c|c|c|c|c|}
\hline \multirow[t]{2}{*}{ Explanatory variable } & \multicolumn{4}{|c|}{ Linear effects } & \multicolumn{3}{|c|}{ Nonlinear effects } \\
\hline & Estimate & $\mathrm{SD}$ & $t$-ratio & $\mathrm{p}(t)$ & df & $F$ & $\mathrm{p}(F)$ \\
\hline \multicolumn{8}{|l|}{ Probability of feeding model } \\
\hline Constant & -354.6867 & 65.6022 & -5.41 & $\mathrm{p}<0.001$ & & & \\
\hline SST & -0.1903 & 0.0280 & -6.79 & $\mathrm{p}<0.001$ & 3 & 16.069 & $\mathrm{p}<0.001$ \\
\hline Weight & 0.0004 & 0.0001 & 6.14 & $\mathrm{p}<0.001$ & 3 & 24.244 & $\mathrm{p}<0.001$ \\
\hline Latitude & 0.0354 & 0.0158 & 2.25 & $\mathrm{p}<0.05$ & & & \\
\hline Longitude & 0.0134 & 0.0064 & 2.08 & $\mathrm{p}<0.05$ & 3 & 9.934 & $\mathrm{p}<0.05$ \\
\hline Year & 0.1795 & 0.0334 & 5.37 & $\mathrm{p}<0.001$ & 3 & 27.276 & $\mathrm{p}<0.001$ \\
\hline DOY & 0.0034 & 0.0017 & 1.99 & $\mathrm{p}<0.05$ & 3 & 21.052 & $\mathrm{p}<0.001$ \\
\hline TOD - DN vs DN + DY & 0.2034 & 0.1046 & 1.94 & $\mathrm{p}<0.05$ & & & \\
\hline TOD - DN vs DY & 0.2520 & 0.0553 & 4.56 & $\mathrm{p}<0.001$ & & & \\
\hline TOD - DN vs NT & 0.2142 & 0.0383 & 5.59 & $\mathrm{p}<0.001$ & & & \\
\hline TOD - DN vs NT + DN & 0.2652 & 0.0682 & 3.89 & $\mathrm{p}<0.001$ & & & \\
\hline $\mathrm{TOD}-\mathrm{DN}$ vs $\mathrm{NT}+\mathrm{DN}+\mathrm{DY}$ & 0.0185 & 0.0249 & 0.75 & ns & & & \\
\hline \multicolumn{8}{|l|}{ Stomach fullness model } \\
\hline Constant & 164.2137 & 43.2437 & 3.80 & $\mathrm{p}<0.001$ & & & \\
\hline SST & 0.1012 & 0.0199 & 5.09 & $\mathrm{p}<0.001$ & & & \\
\hline Weight & 0.0001 & 0.0000 & 2.11 & $\mathrm{p}<0.05$ & 3 & 8.411 & $\mathrm{p}<0.001$ \\
\hline Latitude & -0.0453 & 0.0117 & -3.88 & $\mathrm{p}<0.001$ & 3 & 16.35 & $\mathrm{p}<0.001$ \\
\hline Longitude & 0.0090 & 0.0046 & 1.94 & $\mathrm{p}<0.05$ & 3 & 4.572 & $\mathrm{p}<0.05$ \\
\hline Year & -0.0845 & 0.0220 & -3.84 & $\mathrm{p}<0.001$ & 3 & 16.097 & $\mathrm{p}<0.001$ \\
\hline DOY & -0.0065 & 0.0012 & -5.49 & $\mathrm{p}<0.001$ & 3 & 9.188 & $\mathrm{p}<0.001$ \\
\hline TOD - DN vs DN + DY & 0.4311 & 0.0720 & 5.98 & $\mathrm{p}<0.001$ & & & \\
\hline TOD - DN vs DY & 0.0868 & 0.0349 & 2.48 & $\mathrm{p}<0.05$ & & & \\
\hline TOD - DN vs NT & 0.0124 & 0.0241 & 0.51 & $\mathrm{~ns}$ & & & \\
\hline TOD - DN vs NT + DN & 0.0689 & 0.0506 & 1.36 & ns & & & \\
\hline $\mathrm{TOD}-\mathrm{DN}$ vs $\mathrm{NT}+\mathrm{DN}+\mathrm{DY}$ & 0.0780 & 0.0183 & 4.27 & $\mathrm{p}<0.001$ & & & \\
\hline
\end{tabular}


of the feeding and growth indices are relative measures, and should not be considered a prediction of absolute rates.

\section{RESULTS}

\section{Pooled data}

All 7 explanatory variables were retained in the GAM that achieved the best fits (Table 1). All of the continuous variables, except LAT, were best represented by nonparametric spline smoothers in the probability of feeding model. There was a negative effect of SST (Fig. 1) on feeding probability. The effect of WT on feeding probability increased significantly to an asymptote at approximately $3 \mathrm{~kg}$, with higher variability at weights exceeding $4 \mathrm{~kg}$ (Fig. 1). The effects of LAT and LNG were significant but weak (Fig. 1). Feeding probabilities increased steadily during 1956 to 1960, and remained high through 1964 (Fig. 1). Probabilities of feeding were low during the winter months, and elevated in spring and late summer (Fig. 1). TOD had a significant effect on feeding probability, with the highest feeding probabilities exhibited during the NT and NT + DN periods (Fig. 1).

All independent variables were entered into the model for stomach fullness (Table 1). The effect of SST, YR and TOD showed different patterns relative to feeding probability. Stomach fullness showed a strong, positive, linear relationship with SST (Fig. 1). While feeding probability was low in the early period of the time series (Fig. 1), stomach fullness was high relative to the later years (Fig. 1). Stomach fullness was higher during DN + DY and DY than in NT samples, which is opposite relative to the diel pattern in feeding probability. The percentage of variance accounted for by the feeding probability and stomach fullness models was 13 and $16 \%$, respectively (Table 1 ).

\section{Feeding as a function of season}

During winter, SST, WT and LNG had a significant effect on feeding probability (Table 2). Both SST and WT were entered into the model as linear effects, with the former parameter having a negative effect and the latter parameter a positive effect (Fig. 2). The LNG effect was nonlinear, with high feeding probabilities along the eastern boundary of the study area (Fig. 2). Only SST and YR were entered into the model to explain stomach fullness patterns during winter (Table 2). SST had a significant nonlinear effect on stomach fullness. Stomach fullness was low between 4 and $4.5^{\circ} \mathrm{C}$ (Fig. 3). The feeding probability model accounted for $29 \%$ of the variance in the data, while $26 \%$ of the variance was explained by the stomach fullness model.

\section{Probability of Feeding}
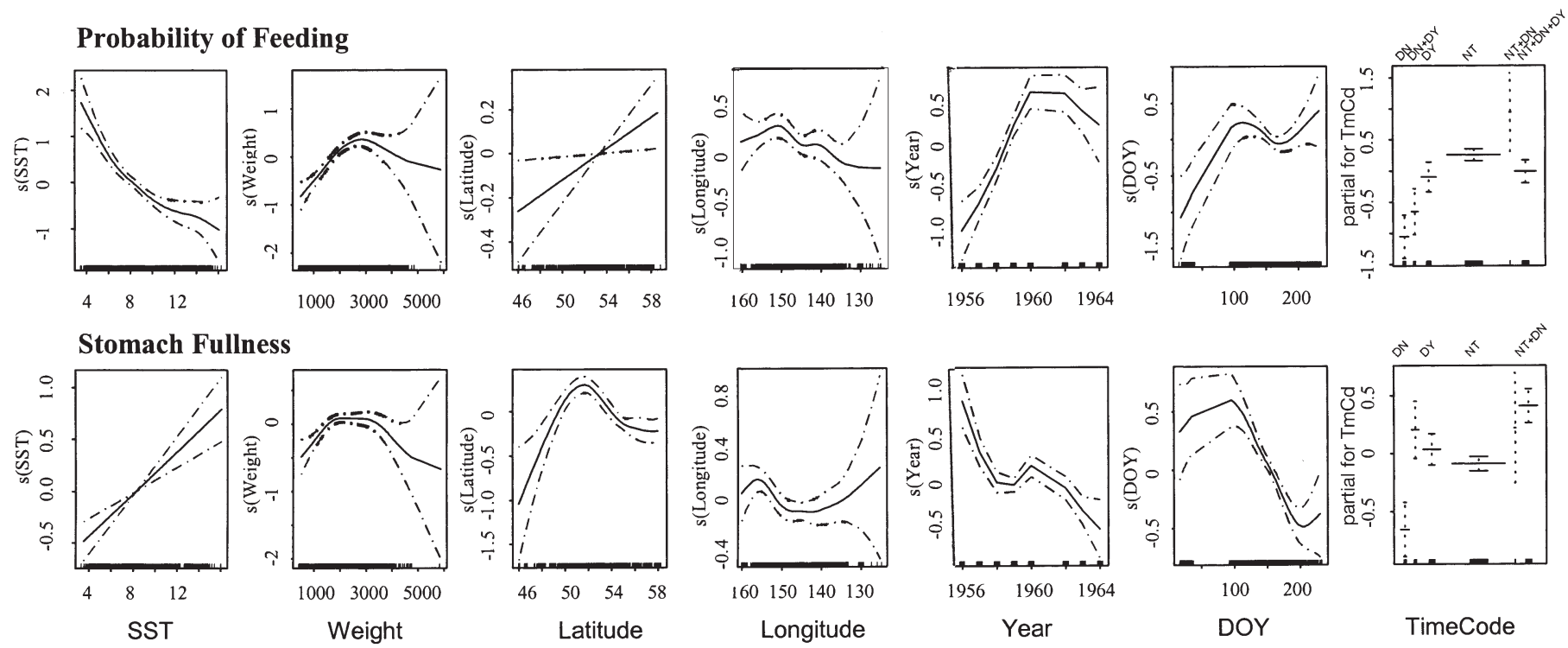

Fig. 1. Oncorhynchus nerka. Plots showing effect of each of the explanatory variables on probability of feeding (top row) and stomach fullness (bottom row) in the generalized additive model, GAM (all data combined). Effect of variables were determined to be either nonlinear (using a spline smoother, $s$ ) or linear (using a partial correlation coefficient, partial) based on a reduced model determined by minimizing an Akaike information criterion statistic. The marks on the $x$-axis indicate sampling intensity. SST: sea surface temperature $\left({ }^{\circ} \mathrm{C}\right)$, Weight: salmon body weight $(\mathrm{g})$, DOY: day of year; DN: dawn; DY: day; NT: night 
Table 2. Oncorhynchus nerka. Summary of parameter estimates to be applied to explanatory variables and statistical tests for GAM on sockeye salmon dietary data collected during winter (January and February, pooled 1963 and 1964). Probability of feeding model: null deviance $=234$ on $171 \mathrm{df}$, residual deviance $=173$ on $165 \mathrm{df}$, quasi-likelihood dispersion parameter $=1$, $\mathrm{R}^{2}=(234-173) / 234=0.26$. Stomach fullness model: null deviance $=170$ on $99 \mathrm{df}$, residual deviance $=143$ on $94 \mathrm{df}$, quasilikelihood dispersion parameter $=1.518, \mathrm{R}^{2}=(170-143) / 170=0.16$. SST: sea surface temperature; ns: not significant

\begin{tabular}{|c|c|c|c|c|c|c|c|}
\hline \multirow[t]{2}{*}{ Explanatory variable } & \multicolumn{4}{|c|}{ Linear effects } & \multicolumn{3}{|c|}{ Nonlinear effects } \\
\hline & Estimate & $\mathrm{SD}$ & $t$-ratio & $\mathrm{p}(t)$ & df & $F$ & $\mathrm{p}(F)$ \\
\hline \multicolumn{8}{|c|}{ Probability of feeding model } \\
\hline Constant & 40.4386 & 11.3017 & 3.58 & & & & \\
\hline SST & -1.7030 & 0.4787 & -3.56 & $\mathrm{p}<0.001$ & & & \\
\hline Weight & 0.0012 & 0.0004 & 3.11 & $\mathrm{p}<0.05$ & & & \\
\hline Longitude & -0.2266 & 0.0623 & -3.64 & $\mathrm{p}<0.001$ & 3 & 14.913 & $\mathrm{p}<0.05$ \\
\hline \multicolumn{8}{|c|}{ Stomach fullness model } \\
\hline Constant & 618.0242 & 519.9885 & 1.19 & & & & \\
\hline SST & 0.1933 & 0.2177 & 0.89 & ns & 3 & 4.7 & $\mathrm{p}<0.05$ \\
\hline Year & -0.3168 & 0.2647 & -1.20 & ns & & & \\
\hline
\end{tabular}

\section{Winter 1963 and 1964}
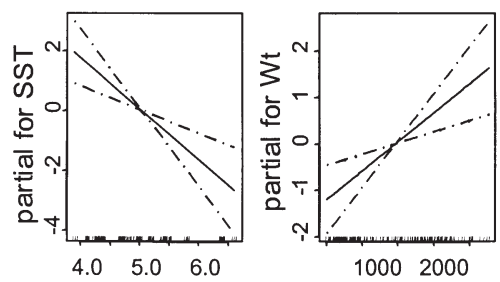

Spring 1962

ns

ns

ns

ns

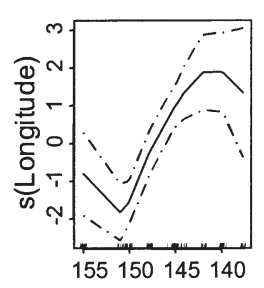

ns

ns

ns

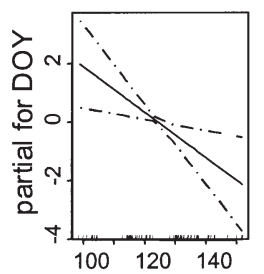

ns

ns

ns

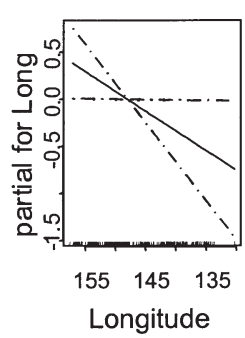

ns

ns

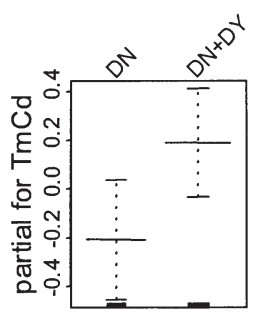

ns

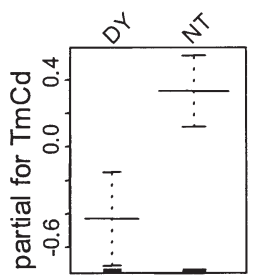

Year

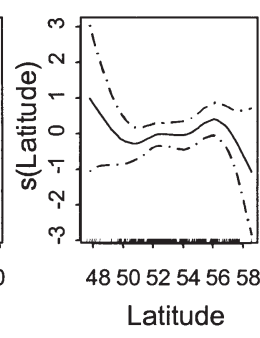

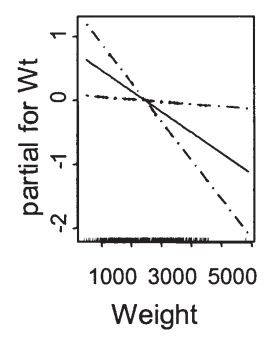

Fig. 2. Oncorhynchus nerka. Plots showing effect of each of the explanatory variables on probability of feeding in the GAM for winter (1963 and 1964 combined), spring (1962 and 1963), and summer (1962). ns: not significant, explanatory variables were dropped from the model; Wt: weight; Long: Longitude; TmCd: timecode; further details as in Fig. 1 
Winter 1963 \& 1964

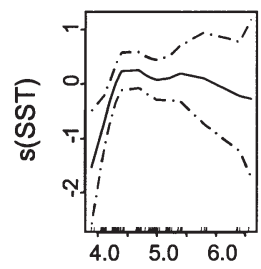

NS

NS

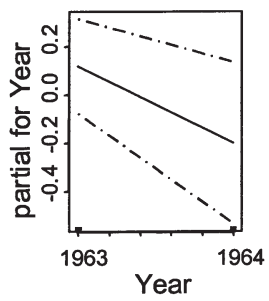

Spring 1962

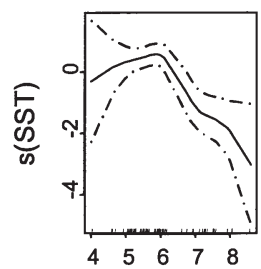

NS

NS

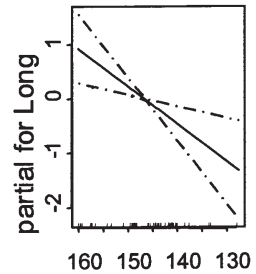

NS
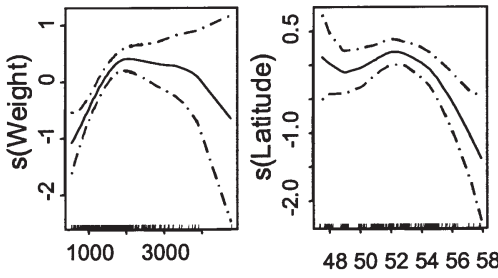

Summer 1962

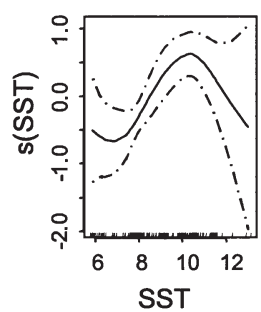

NS

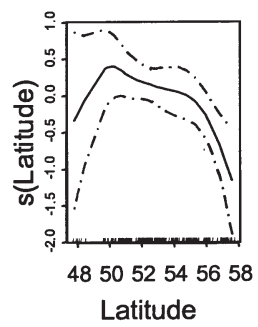

NS

NS

$\begin{array}{lll}150 & 140 \quad 130\end{array}$

NS

Longitude
Stomach Fullness

NS

NS

Fig. 3. Oncorhynchus nerka. Plots showing effect of each of the explanatory variables on stomach fullness in the GAM for winter

(1963 and 1964 combined), spring (1962 and 1963), and summer (1962). Further details as in Figs. 1 \& 2

Table 3. Oncorhynchus nerka. Summary of parameter estimates to be applied to explanatory variables and statistical tests for GAM on sockeye salmon dietary data collected during spring 1962 (April and May). Probability of feeding model: null deviance $=80$ on $96 \mathrm{df}$, residual deviance $=71$ on $95 \mathrm{df}$, quasi-likelihood dispersion parameter $=1, \mathrm{R}^{2}=(80-71) / 80=0.11$. Stomach fullness model: null deviance $=179$ on $76 \mathrm{df}$, residual deviance $=117$ on $71 \mathrm{df}$, quasi-likelihood dispersion parameter $=1.646$,

$\mathrm{R}^{2}=(179-117) / 179=0.35$. SST: sea surface temperature; DOY: day of year

\begin{tabular}{|lcccccc|}
\hline Explanatory variable & \multicolumn{4}{c}{ Linear effects } & & \multicolumn{2}{c|}{ Nonlinear effects } \\
& Estimate & SD & $t$-ratio & $\mathrm{p}(t)$ & df & \\
\hline Probability of feeding model & & & & & \\
Constant & 11.7538 & 3.5871 & 3.27 & & \\
DOY & -0.0778 & 0.0271 & -2.86 & $\mathrm{p}<0.05$ & \\
Stomach fullness model & & & & \\
Constant & 12.2525 & 3.9603 & 3.09 & & 5.531 \\
SST & -0.7699 & 0.1709 & -4.51 & $\mathrm{p}<0.001$ & & \\
Longitude & -0.0688 & 0.0237 & -2.91 & $\mathrm{p}<0.05$ & & \\
\hline
\end{tabular}


Table 4. Oncorhynchus nerka. Summary of parameter estimates to be applied to explanatory variables and statistical tests for GAM on sockeye salmon dietary data collected during spring 1963 (April and May). Probability of feeding model: null deviance = 541 on $430 \mathrm{df}$, residual deviance $=510$ on $427 \mathrm{df}$, quasi-likelihood dispersion parameter $=1, \mathrm{R}^{2}=(541-510) / 541=0.06$ Stomach fullness model: null deviance $=410$ on $264 \mathrm{df}$, residual deviance $=326$ on $253 \mathrm{df}$, quasi-likelihood dispersion parameter $=1.428, \mathrm{R}^{2}=$ $(410-326) / 410=0.21$. SST: sea surface temperature; DOY: day of year; TOD: time of day; DN: dawn; DY: day; ns: not significant

\begin{tabular}{|c|c|c|c|c|c|c|c|}
\hline \multirow{2}{*}{ Explanatory variable } & \multicolumn{4}{|c|}{ Linear effects } & \multicolumn{3}{|c|}{ Nonlinear effects } \\
\hline & Estimate & $\mathrm{SD}$ & $t$-ratio & $\mathrm{p}(t)$ & $\mathrm{df}$ & $F$ & $\mathrm{p}(F)$ \\
\hline \multicolumn{8}{|c|}{ Probability of feeding model } \\
\hline Constant & 1.7969 & 0.8532 & 2.11 & & & & \\
\hline SST & -0.3330 & 0.1231 & -2.71 & $\mathrm{p}<0.05$ & & & \\
\hline Weight & 0.0006 & 0.0002 & 3.38 & $\mathrm{p}<0.001$ & & & \\
\hline TOD - DN vs DN + DY & 0.1986 & 0.1165 & 1.71 & $\mathrm{p}<0.05$ & & & \\
\hline \multicolumn{8}{|l|}{ Stomach fullness model } \\
\hline Constant & 0.3985 & 1.9480 & 0.21 & & & & \\
\hline SST & 0.2085 & 0.0859 & 2.43 & $\mathrm{p}<0.05$ & & & \\
\hline Weight & 0.0004 & 0.0001 & 3.428 & $\mathrm{p}<0.001$ & 3 & 6.417 & $\mathrm{p}<0.001$ \\
\hline Latitude & -0.0493 & 0.0357 & -1.38 & ns & 3 & 4.401 & $\mathrm{p}<0.05$ \\
\hline DOY & -0.0188 & 0.0064 & -2.93 & $\mathrm{p}<0.05$ & & & \\
\hline TOD - DN vs DN + DY & -0.2394 & 0.0909 & -2.63 & $\mathrm{p}<0.05$ & & & \\
\hline
\end{tabular}
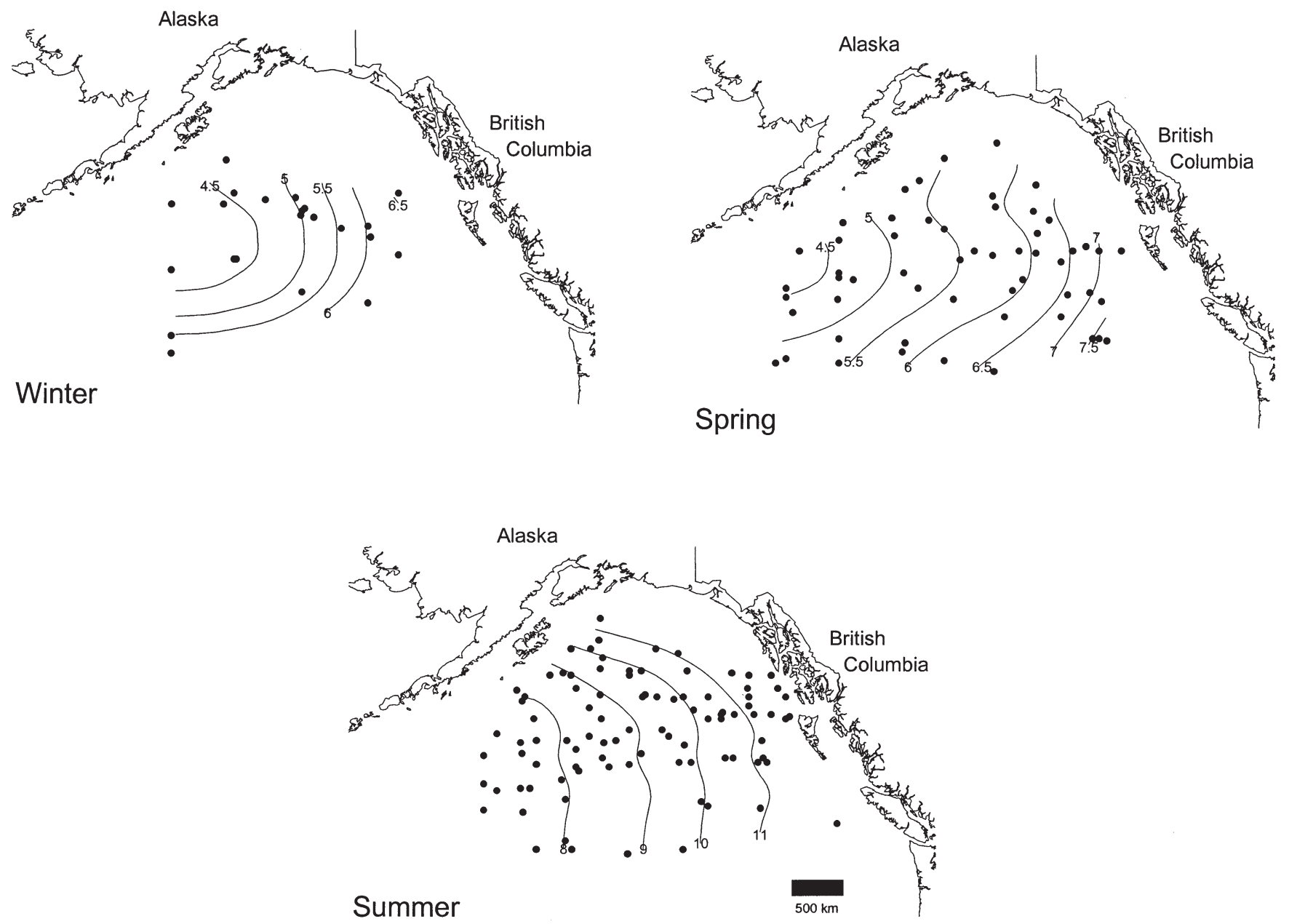

Fig. 4. Sampling stations and interpolated sea surface temperatures during winter (1963 and 1964 combined), spring (1963) and summer (1962) in the Gulf of Alaska 
For the spring of 1962, the reduced form of the feeding probability model included only the effect of DOY, and showed a linear reduction in the response variable over time (Table 3, Fig. 2). Both SST and LNG were included in the reduced model for stomach fullness during this period (Table 3). Stomach fullness was high at temperatures of $6^{\circ} \mathrm{C}$, and declined linearly from west to east (Fig. 3). For the spring of 1963, the reduced form of the feeding probability model included the effects of SST, WT and TOD (Table 4). SST had a negative effect on feeding probability, while WT had a positive effect (Fig. 2). Feeding probability was higher during DN + DY than DY (Fig. 2). SST, WT, LAT, DOY and TOD were all included in the reduced model for stomach fullness (Table 4). SST and DOY had a positive and negative linear effect, respectively, on stomach fullness, while WT and LAT had nonlinear effects (Fig. 3). Stomach fullness decreased at lower WT and higher latitudes (Fig. 3). The feeding probability and stomach fullness models accounted for 18 and $15 \%$ of the variance in the data, respectively.

WT, LAT, LNG and TOD were all retained in the final model to explain feeding probability during summer 1962 (Table 5). Both WT and LNG had a negative, linear effect on feeding probability (Fig. 2). The probability of feeding at NT was higher than during DY. SST, LAT, and DOY were significant in predicting stomach fullness, with the former 2 showing nonlinear effects, and the latter a negative, linear effect (Fig. 3). Stomach fullness appeared to peak at approximately $10^{\circ} \mathrm{C}$ (Fig. 3). Salmon captured at lower latitudes exhibited higher stomach fullness than those in the northern region of the study area (Fig. 3). The feeding probability and stomach fullness models accounted for 8 and $10 \%$ of the variance in the data, respectively.

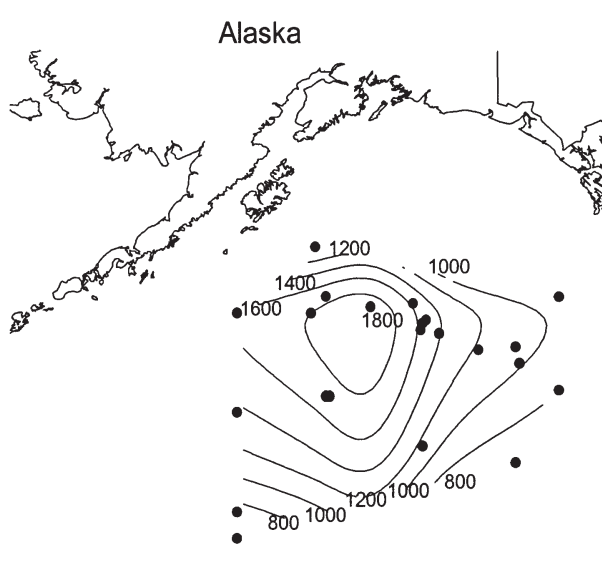

Winter

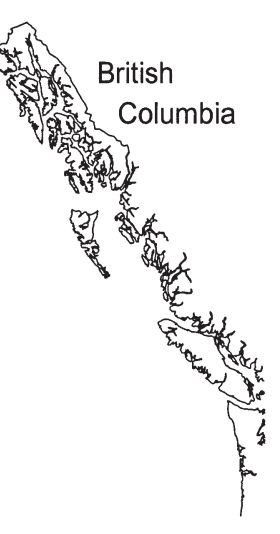

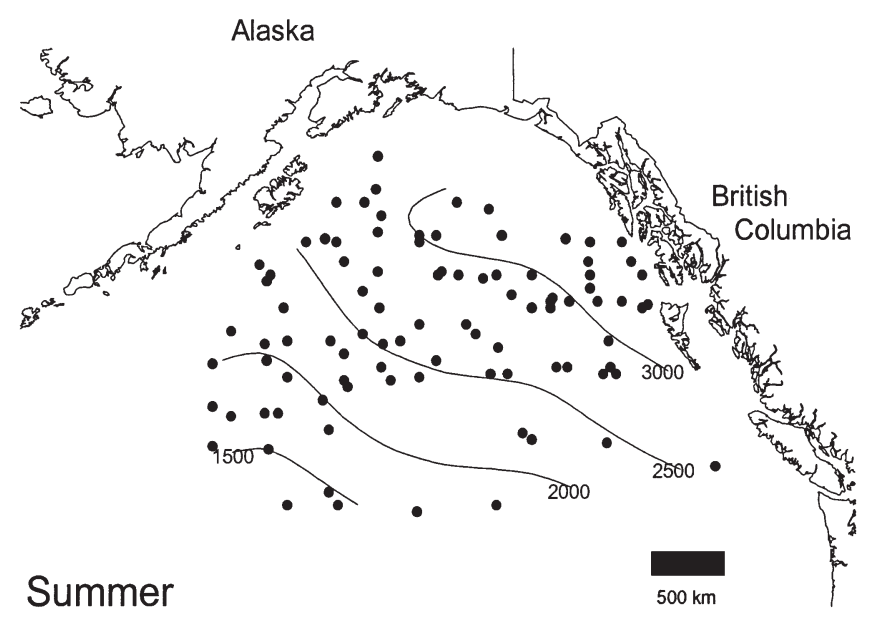

Fig. 5. Oncorhynchus nerka. Sampling stations and interpolated sockeye body weights during winter (1963 and 1964 combined), spring (1963) and summer (1962) in the Gulf of Alaska 
Table 5. Oncorhynchus nerka. Summary of parameter estimates to be applied to explanatory variables and statistical tests for GAM on sockeye salmon dietary data collected during summer 1962 (June to August). Probability of feeding model: null deviance $=419$ on $389 \mathrm{df}$, residual deviance $=387$ on $382 \mathrm{df}$, quasi-likelihood dispersion parameter $=1, \mathrm{R}^{2}=(419-387) / 419=0.08$. Stomach fullness model: null deviance $=777$ on $300 \mathrm{df}$, residual deviance $=703$ on $291 \mathrm{df}$, quasi-likelihood dispersion parameter $=1.428, \mathrm{R}^{2}=$ $(777-703) / 777=0.10$. SST: sea surface temperature; DOY: day of year; TOD: time of day; NT: night; DY: day; ns: not significant

\begin{tabular}{|c|c|c|c|c|c|c|c|}
\hline \multirow[t]{2}{*}{ Explanatory variable } & \multicolumn{4}{|c|}{ Linear effects } & \multicolumn{3}{|c|}{ Nonlinear effects } \\
\hline & Estimate & $\mathrm{SD}$ & $t$-ratio & $\mathrm{p}(t)$ & df & $F$ & $\mathrm{p}(F)$ \\
\hline \multicolumn{8}{|c|}{ Probability of feeding model } \\
\hline Constant & -6.4855 & 4.8507 & -1.34 & & & & \\
\hline Weight & -0.0003 & 0.0002 & -2.23 & $\mathrm{p}<0.05$ & & & \\
\hline Latitude & 0.0434 & 0.0624 & 0.70 & $\mathrm{~ns}$ & 3 & 9.692 & $\mathrm{p}<0.05$ \\
\hline Longitude & -0.0421 & 0.0209 & -2.02 & $\mathrm{p}<0.05$ & & & \\
\hline TOD - DY vs NT & 0.3813 & 0.1255 & 3.04 & $\mathrm{p}<0.05$ & & & \\
\hline \multicolumn{8}{|c|}{ Stomach fullness model } \\
\hline Constant & 8.9227 & 2.6908 & 3.32 & & & & \\
\hline SST & 0.2386 & 0.0799 & 2.99 & $\mathrm{p}<0.05$ & 3 & 3.783 & $\mathrm{p}<0.05$ \\
\hline Latitude & -0.1215 & 0.0450 & -2.70 & $\mathrm{p}<0.05$ & 3 & 2.850 & $\mathrm{p}<0.05$ \\
\hline DOY & -0.0417 & 0.0119 & -3.51 & $\mathrm{p}<0.001$ & & & \\
\hline
\end{tabular}
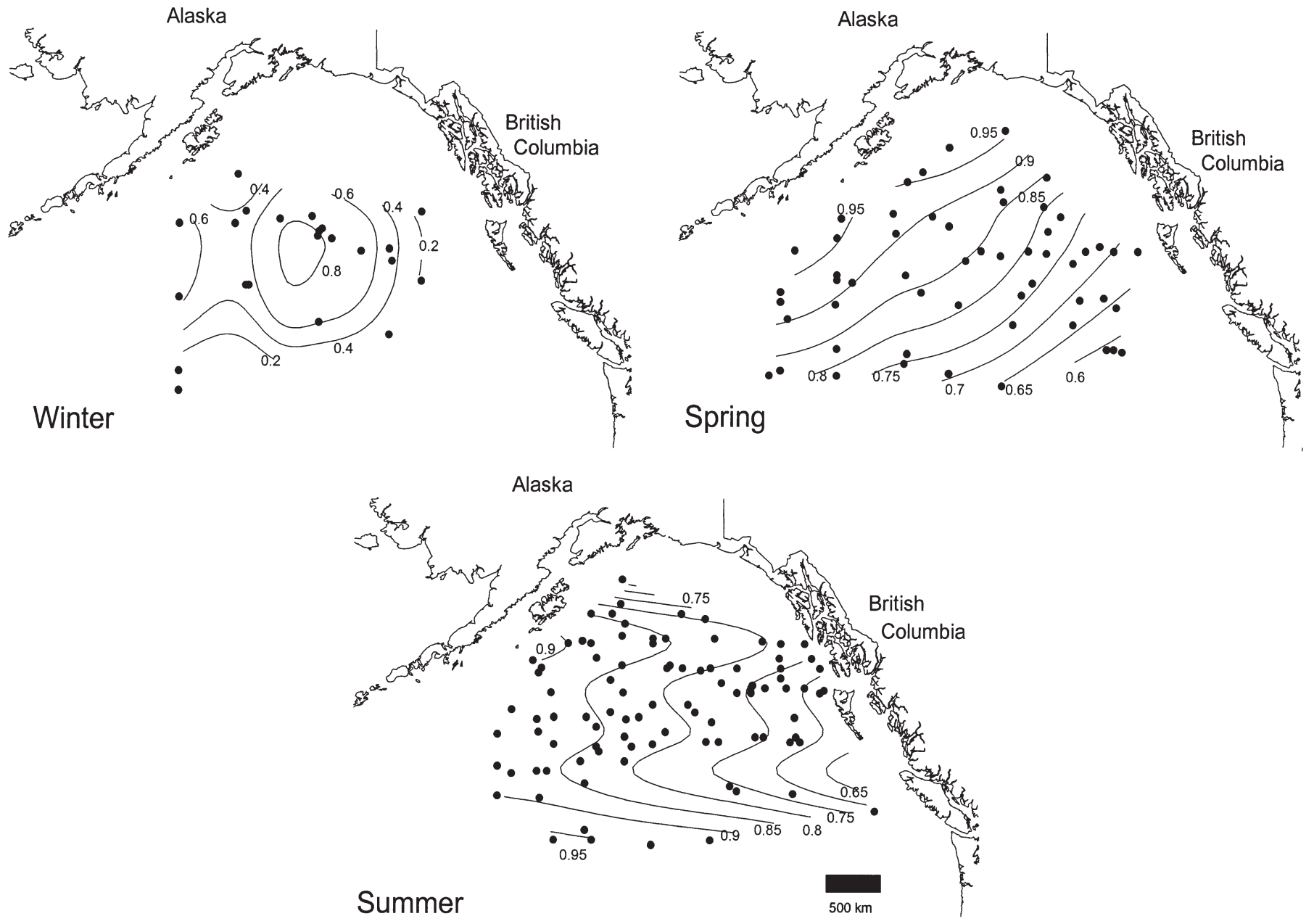

Fig. 6. Oncorhynchus nerka. Sampling stations and predictions of feeding probability during winter (1963 and 1964 combined), spring (1963) and summer (1962) in the Gulf of Alaska 

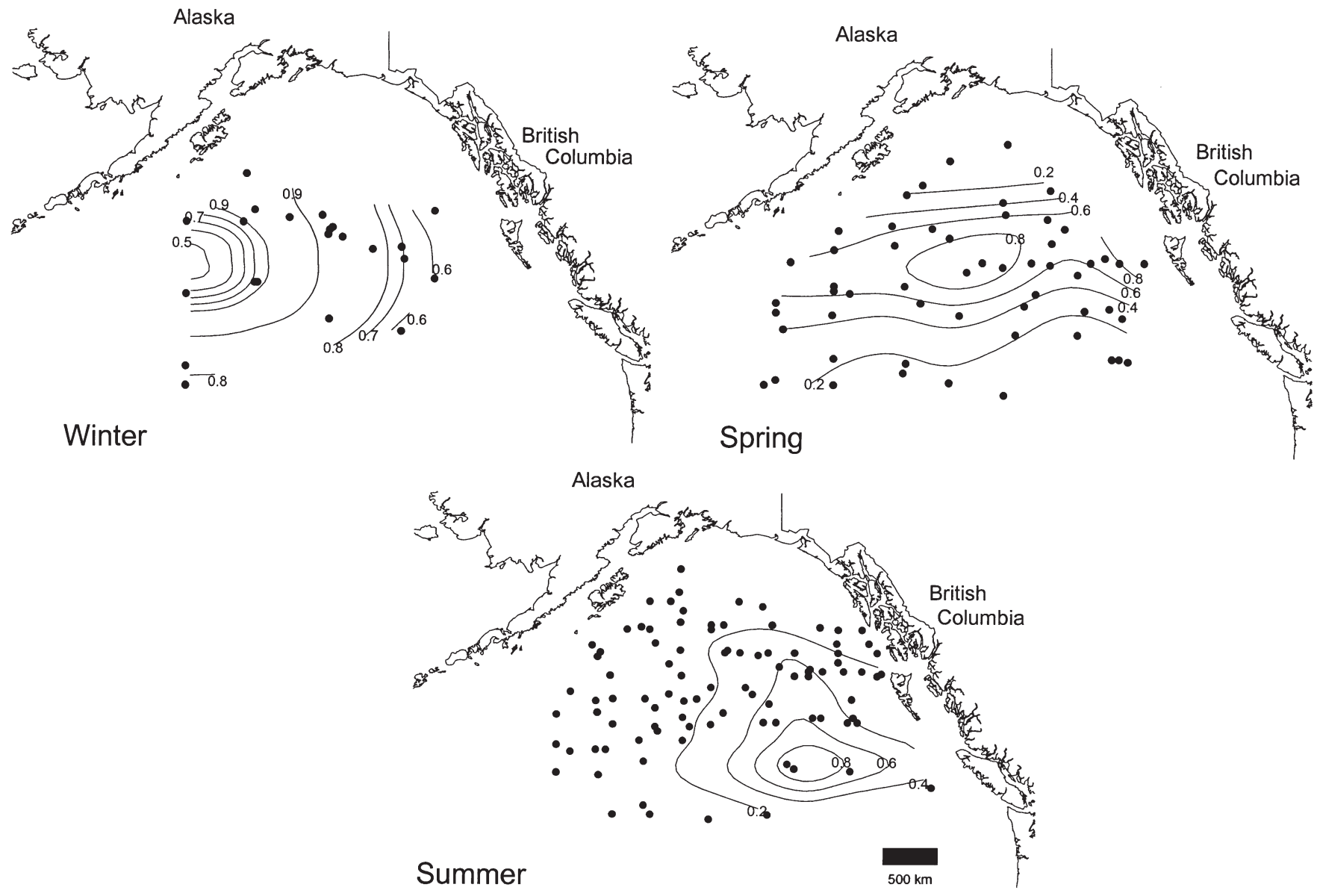

Fig. 7. Oncorhynchus nerka. Sampling stations and predictions of stomach fullness during winter (1963 and 1964 combined), spring (1963) and summer (1962) in the Gulf of Alaska

\section{Seasonal and spatial patterns in SST, body weights, feeding and growth indices}

Sea-surface temperature trends during winter and spring showed a marked trend of cooler water in the northwest region of the gulf $\left(\mathrm{ca} .4 .5^{\circ} \mathrm{C}\right)$, grading to warmer temperatures in the southeast (ca. $6.5^{\circ} \mathrm{C}$ during winter, $7.5^{\circ} \mathrm{C}$ during spring: Fig. 4). The patterns of surface temperatures differed during summer 1962. Temperatures were cool in the southwest (ca. $8^{\circ} \mathrm{C}$ ), grading to warmer waters in the northeast (ca. $11^{\circ} \mathrm{C}$ ). The interpolation of sockeye salmon body weights revealed that larger individuals were captured in the north central gulf during winter, in the northwest region during spring (for both 1962 and 1963), and in the northeast during summer 1962 (Fig. 5).

Prediction of feeding probability using the GAMs revealed a region of high feeding probability in the central gulf during winter, in the northwest region during spring 1963, and in the western regions during summer 1962 (Fig. 6). Normalized stomach fullness predictions from the GAMs revealed peaks in the central part of the gulf during winter and spring 1963 and in the southeast during summer 1962 (Fig. 7). The growth rate index, GRI (computed using the product of feeding probability and stomach fullness and accounting for bioenergetic losses), was highest in the central part of the gulf during winter and spring 1963 and in the southeast during summer 1962 (Fig. 8). The region supporting positive growth potential (demarcated by the 'zero growth' isopleth) lay between latitudes $\sim 48^{\circ} \mathrm{N}$ and $55^{\circ} \mathrm{N}$ during spring 1963, and to the southeast during summer 1962 (Fig. 8). GRI values were much more variable over latitude, with a noticeable reduction in GRI along the southern periphery of the gulf.

Accounting for bioenergetic losses in the GRI did not significantly alter the spatial patterns observed in FI. The latitudinal variations in FI observed particularly in winter and spring were driven in part by a distinct gradient of increasing mean size of sockeye from south 

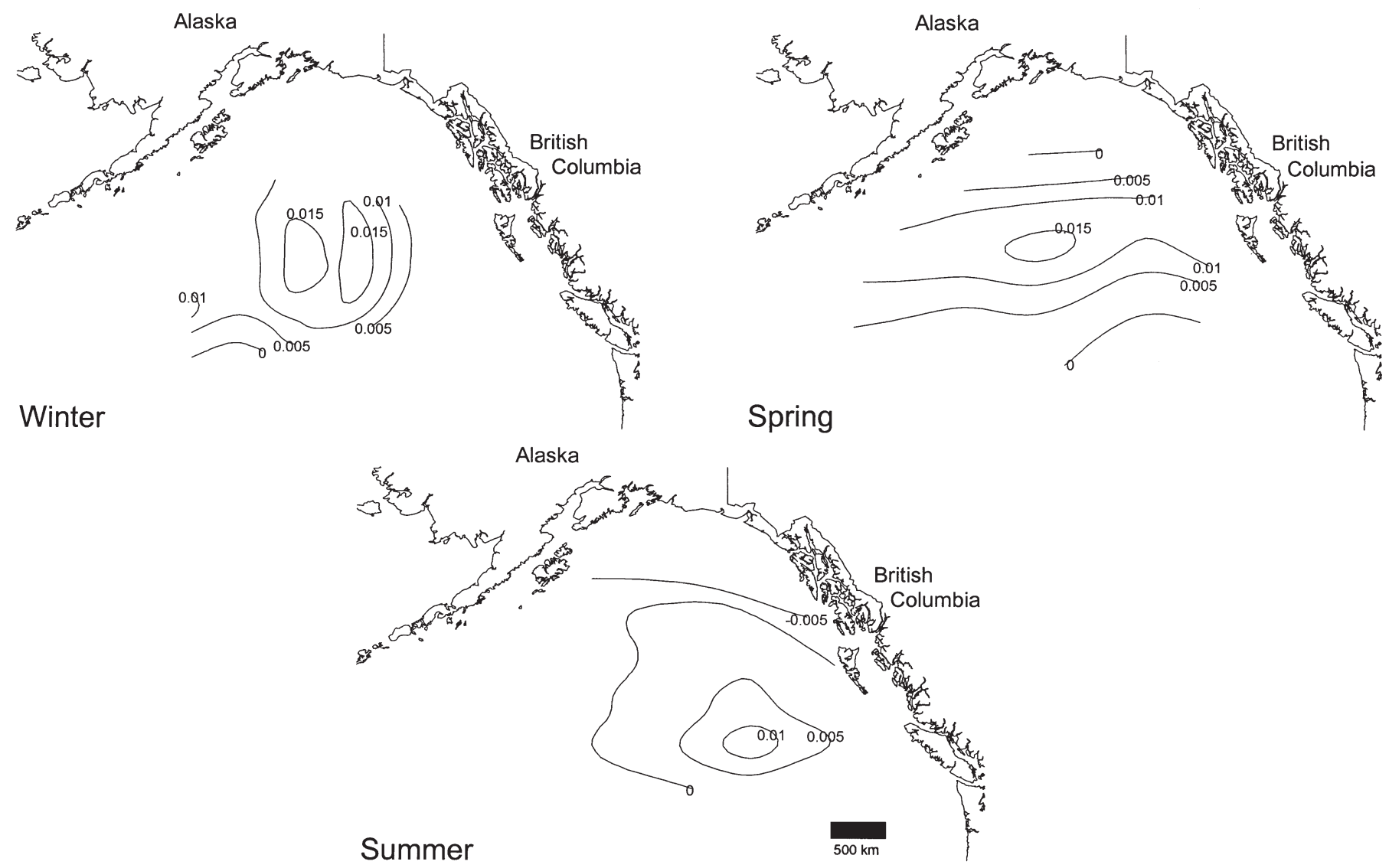

Fig. 8. Oncorhynchus nerka. Sampling stations and predictions of a growth index during winter (1963 and 1964 combined), spring (1963) and summer (1962) in the Gulf of Alaska

to north within the study area (recall that feeding probability and stomach fullness were positively related to body size during winter and spring, see 'Pooled data' and 'Feeding as a function of season'). Both FI and GRI was highest in the southeast during summer owing to the observed trends of increased stomach fullness at warmer temperatures and lower latitudes during summer.

Spatial patterns of SST, WT, stomach fullness and GRI were generally consistent between spring 1962 and 1963. Water temperature during spring 1962 were somewhat elevated compared to 1963, but the spatial pattern was similar (Figs. 4 \& 9). The spatial pattern in body sizes of sockeye in the Gulf during spring 1962 was also similar to that observed in spring 1963 (Figs. 5 $\& 9)$. While feeding probability was a function of DOY only, stomach fullness, FI and GRI were all higher in the northeast region of the gulf during spring 1962 (Fig. 9). The pattern observed in GRI during spring 1962 was similar to that observed during spring 1963, with a strong latitudinal gradient and a sharp reduction in GRI along the southern periphery of the gulf (Figs. 8 \& 9).

\section{DISCUSSION}

Feeding and growth indices applied to sockeye salmon varied both temporally and spatially within the Gulf of Alaska. Feeding probability was highest during spring and summer, whereas stomach fullness was high during winter and spring. Larger sockeye exhibited higher values of feeding probability and stomach fullness during winter and spring, even after correcting for allometry. The trend for feeding probability was reversed during summer, presumably due to cessation of feeding prior to initiation of the spawning migration. The region of highest feeding and growth appears to shift spatially as a function of seasons. During the years examined, peak feeding and growth within the Gulf of Alaska shifted from a central position during winter and spring to a southeastern position during summer. This period spans approximately the last 6 to 7 mo of marine residency prior to initiation of the spawning migration for most stocks of sockeye salmon. Finally, GRI graded from positive to negative over a very narrow range of temperature (ca. $1^{\circ} \mathrm{C}$ ) and latitude $\left(<3^{\circ}\right)$. This pattern was particularly evident during spring. 
These results have a bearing on hypotheses involving the high-seas distribution of salmon and migration patterns. The patterns observed in FI and GRI during winter suggest a fitness advantage that can be gained by residency near the center of the gulf. This is in contrast with the conventional understanding of a southern distribution of sub-adults in the Gulf of Alaska during winter (reviewed in Burgner 1991). Based on surveys conducted during December 1992 and January 1996 Welch et al. (1998) noted that salmon were generally restricted to waters cooler than $7.4^{\circ} \mathrm{C}$, which suggests a more northern distribution of the fish during this time of year. This may point to an adaptive trait of northern migration late in the year prior to undertaking the spawning migration. The sampling during winter was limited ( $\mathrm{n}=183$ ), thus the hypothesis regarding spatial patterns in habitat quality during this season needs to be further tested with additional data.

Values of FI and GRI were maximum near the central (during 1963) and northeastern (during 1962) regions of the gulf during spring. A band of elevated feeding and growth was located between latitude $52^{\circ}$ and $55^{\circ} \mathrm{N}$,

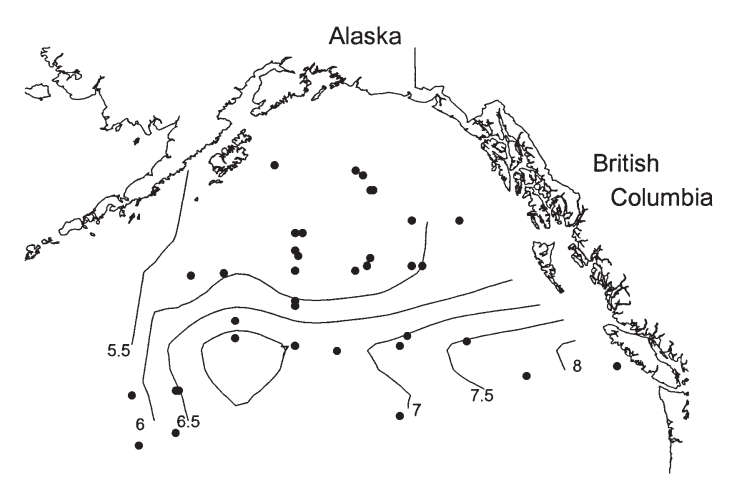

Sea Surface Temperature

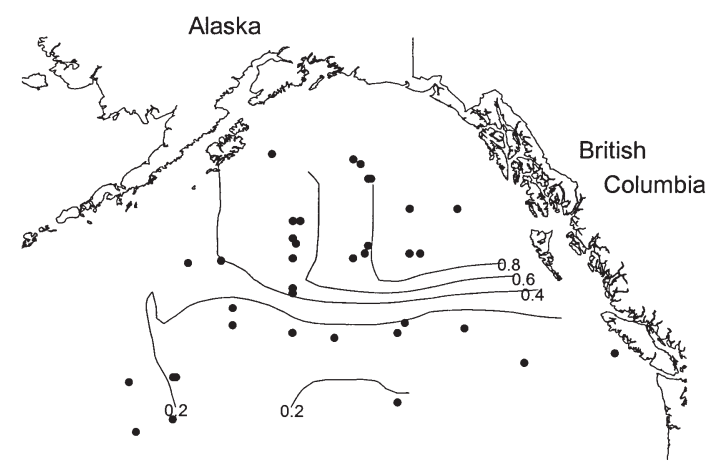

Stomach Fullness which represents the boundaries of the Subarctic Current (Dodimead et al. 1963). I noted a marked decline in feeding and growth south of latitude $52^{\circ} \mathrm{N}$. Both FI and GRI declined by an order of magnitude over approximately $1^{\circ} \mathrm{C}$ and $3^{\circ}$ of latitude. The reduction in GRI along the northern, eastern and western boundaries of the study area estimated using the spring 1962 data were much less pronounced than that observed in the south. This suggests the existence of a strong frontal feature, and may help explain the existence of the sharp reduction in salmon catch rates across this region described by Welch et al. $(1995,1998)$. Welch et al. posited that the reduction in catch rates could only be explained by the existence of a behavioral avoidance of a threshold SST value. I contend a growth-optimization hypothesis is equally plausible based on the results reported herein. SST and prey availability probably covary near the southern boundary of suitable salmon habitat. The results of this study suggest that feeding success during spring declines markedly above approximately $7^{\circ} \mathrm{C}$ (or below latitude $52^{\circ} \mathrm{N}$ ). This prey effect appears to have a much stronger influence on growth

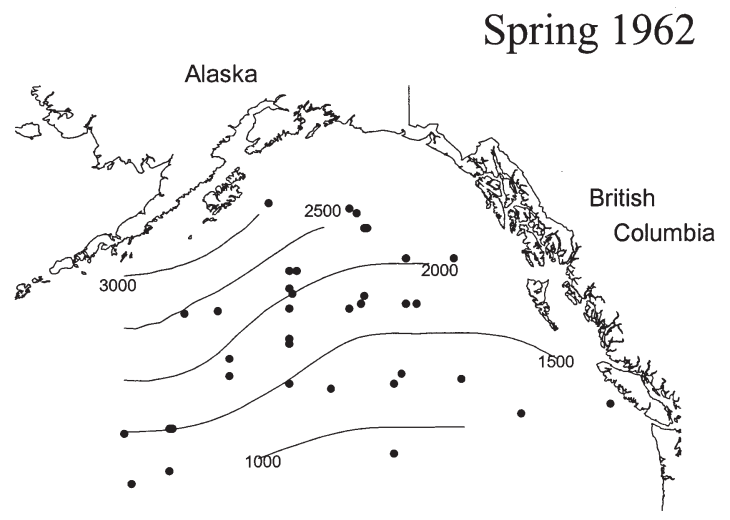

Sockeye Body Weight

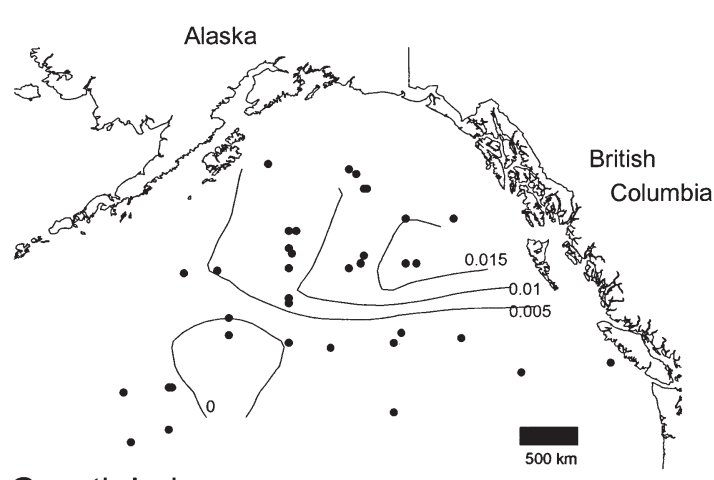

Growth Index

Fig. 9. Oncorhynchus nerka. Sampling stations, interpolations of sea surface temperatures and body weights, and predictions of stomach fullness and a growth index during spring 1962 in the Gulf of Alaska 
than the response of metabolism to temperature, given the narrow range of SST (ca. $1^{\circ} \mathrm{C}$ ) observed along this front. By explicitly incorporating foraging dynamics into a bioenergetic analysis, one can construct a growth performance function that is assymetric with respect to sea surface temperature. This function, expressed spatially in Figs. 8 \& 9, provides a parsimonious explanation of the existence of this distinct southern boundary in the distribution of sockeye salmon during spring in the Gulf of Alaska. One should therefore be cautious about inferring changes in suitable habitat for salmon based solely on expected changes in SST resulting from climate change in the North Pacific. A better understanding of how these expected changes in climate may influence lower food-web dynamics appears to be of critical importance for projecting future shifts in suitable salmon habitats and growth rates in the marine environment. Hinch et al. (1995b), for example, predicted lower growth rates of Fraser River sockeye salmon using a bionergetic modeling approach that incorporated both warmer SST and lower food availability based on expected reductions in wind-driven gyre upwelling.

I found a distinct east-west band of favorable feeding and growth for sockeye salmon straddling latitude $52^{\circ} \mathrm{N}$ during the summer, with a peak in the southeastern region of the gulf. The southern band results from the importance of squid in this region, as noted elsewhere (LeBrasseur 1966, Pearcy et al. 1988). It should be noted that although the mean ration is elevated in this region, variability in feeding appeared to be high. This suggests a high, but more variable, energetic payoff resulting from foraging in this area. Squid distribution may be highly aggregated, and the observed patterns of variability in feeding probability and stomach fullness may result from this spatially heterogeneous distribution. Furthermore, Pearcy et al. (1988) also document that the squid Berryteuthis anonychus, found commonly in stomachs of salmon in the Subarctic Current, are substantially larger (mantle length range of 75 to $105 \mathrm{~mm}$ ) than the species found in the Ridge Domain and Alaskan Current (Gonatus middendorffi, mantle length range 30 to $75 \mathrm{~mm}$ ). These larger sized squid found in the Subarctic Current may represent a more significant source of energy for foraging salmon. In addition, squid are known to exhibit high caloric content relative to other salmon prey (Davis 1993), underscoring the importance of this prey item during the latter part of their marine life history.

Salmon size appeared to be a strong predictor of feeding probability and stomach fullness. My feeding index incorporated an allometric relationship that standardized prey weights in the stomach (Eq. 1). Any further trend in this feeding index as a function of body weight can be interpreted within an ecological context. I found a very consistent asymptotic relationship in both feeding probability and stomach fullness with respect to body weight during winter and spring, suggesting some form of ecological limitation on feeding among small size classes of sockeye salmon (generally $<2 \mathrm{~kg}$ ). These fish probably face a higher mortality risk at small body sizes (e.g. see Furnell \& Brett 1986), and the body size-feeding relationship reported here is consistent with the hypothesis that smaller fish must actively trade-off foraging time with risk-aversion behaviors toward potential predators. Adopting these behaviors generally leads to latency in feeding and may result in significant energetic losses. This conclusion is speculative, but deserves continued investigation. The reversal of this trend in summer (negative effect of weight on feeding probability) suggests that the fish are maturing and cease feeding prior to making landfall at the initiation of their spawning migration.

The pattern of larger fish in cooler waters during the springs of 1962 and 1963 may be a result of body sizedependent competitive interactions. Hughes \& Grand (2000) crafted a model that combines the Ideal Free Distribution (IFD) theory with physiological growth principles that help explain the common observation of larger fish occupying cooler waters. These authors hypothesize that if, in resource-limited environments, competitive abilities increase more slowly with increasing body size than maximum ration, then larger fish will tend to occupy cooler water as a means to reduce food demand. This size segregation during the spring was very striking in both years, with large fish (>2.5 kg) occupying relatively cool waters $\left(5.5\right.$ to $\left.6^{\circ} \mathrm{C}\right)$ and smaller fish (ca. $1 \mathrm{~kg}$ ) residing in waters $>7^{\circ} \mathrm{C}$. This pattern appeared to be reversed during summer, with larger fish in warmer waters. This may result from the fact that squid represent an important diet item for larger fish, and squid are generally more available in the southern warmer waters of the Gulf of Alaska (described above). In addition, feeding by large adult salmon in warmer southern waters off the continental shelf may be accelerated in preparation for an energetically demanding spawning migration during midsummer. This increased feeding motivation could help explain the higher feeding and growth indices in the extreme southeastern region of the study area.

The use of GAMs in the present study provided a useful method of incorporating a number of potentially important variables. One problem with applying this type of approach to dietary data collected at fixed locations is violation of the assumption of independence of samples. This problem was identified by Stefansson \& Palsson (1997) in their study of cod dietary habits (referred to in their paper as 'intra-haul correlation'). This may provide some explanation as to why the GAM did not account for a great deal of the the variability in the data (range 6 to $35 \%$ ). I concur with Stefansson \& Palsson (1997) that the 
GAM does not adequately address microscale variance in the data; however, the approach does provide a useful method of discerning the larger-scale patterns that were of interest in the present study. To help determine whether the violation of this sample-independence assumption may influence the conclusions drawn in this study, I conducted a separate analysis and calculated the proportion of fish feeding and the mean stomach fullness of fish observed with prey at each station. This effectively reduced my overall degrees of freedom in the analysis from 3817 to 383 . I used a GLM and GAM to predict stomach fullness and my feeding index (in this case, proportion of fish at each station with observed prey in their stomach multiplied by mean stomach fullness of feeding fish). All explanatory variables in the stomach fullness model were significant $(p \leq 0.05)$, and all variables with the exception of weight displayed nonlinear effects. All the variables, with the exception of latitude, accounted for a significant amount of variance in FI ( $p \leq 0.13$ for latitude, $p \leq 0.05$ for the remaining factors). WT and YR had a linear effect on FI, whereas the other significant variables showed nonlinear effects. The results of this conservative test suggest that the results reported herein are robust given the uncertainty in ascribing degrees of freedom in the statistical tests.

The low proportion of variance accounted for in the GAM analysis may also indicate that other unmeasured variables may be important in driving diet and feeding habits. For example, density of competitors (conspecifics and other fishes) may also help explain the observed variation in the dietary data. I did not explore effects of density-dependence of feeding and growth in this analysis because of uncertainty in using catch rates as a measure of predator density at each of the sampling stations. The role of density-dependence of growth during the salmon marine-life history has been debated for some years. I anticipate that our understanding will increase as a result of continued retrospective approaches contrasting oceanographic conditions across decadal time scales (e.g. see Tadokoro et al. 1996). These regimes provide strong contrasts, from which ecologists can distinguish causal mechanisms that influence the growth and mortality of important fish stocks. An additional reason for not exploring density-dependent processes is the fact that movement and migration processes are highly dynamic phenomena owing to the swimming capacity of salmon and the recognized role of ocean currents in advection (Rand et al. 1997, Walter et al. 1997). A more rigorous evaluation of the potential role of densitydependence requires a coupled data-modeling approach that can explore different migration patterns of salmon within the context of a physically and biologically dynamic ecosystem. It is hoped that this study will help spawn such efforts.
Acknowledgements. The author was supported partly by an NSERC strategic grant at the University of British Columbia. This is Contribution Number 224 of the US GLOBEC program, jointly funded by the National Science Foundation and the National Oceanic and Atmospheric Administration. The author wishes to thank Andrew Lotto for digital conversion of the raw data, and Mike Healey and Scott Hinch for helpful discussions and support.

\section{LITERATURE CITED}

Anma G, Masuda K, Kobayashi G, Yamguchi H, Meguro T, Sasaki S, Ohtani K (1990) Oceanographic structures and changes around the Transition Domain along $180^{\circ}$ longitude, during June 1979-1988. Bull Fac Fish, Hokkaido Univ 41:73-88

Beauchamp DA, Stewart DJ, Thomas GL (1989) Corroboration of a bioenergetics model for sockeye salmon. Trans Am Fish Soc 118:597-607

Brandt SB (1993) The effect of thermal fronts on fish growth: a bioenergetics evaluation of food and temperature. Estuaries 16:142-159

Brandt SB, Mason DM, Patrick EV (1992) Spatially explicit models of fish growth rate. Fisheries (Bethesda) 17:23-33

Brodeur RD, Ware DM (1992) Long-term variability in zooplankton biomass in the subarctic Pacific Ocean. Fish Oceanogr 1:32-38

Brodeur RD, Ware DM (1995) Interdecadal variability in distribution and catch rates of epipelagic nekton in the Northeast Pacific Ocean. Can Spec Publ Fish Aquat Sci 121:329-356

Burgner RL (1991) Life history of sockeye salmon Oncorhynchus nerka. In: Groot C, Margolis L (eds) Pacific salmon life histories. University of British Columbia Press, Vancouver, p 3-117

Davis ND (1993) Caloric content of oceanic zooplankton and fishes for studies of salmonid food habits and their ecologically related species. NPAFC Document, FRI-UW-9312. Fisheries Research Institute, University of Washington, Seattle

Dodimead AJ, Favorite F, Hirano T (1963) Review of the oceanography of the subarctic Pacific region. Int North Pac Fish Comm Bull 13:1-195

Elliot JM (1991) Rates of gastric evacuation in piscivorous brown trout, Salmo trutta. Fresh Biol 25:297-305

Furnell DJ, Brett JR (1986) Model of monthly marine growth and natural mortality for Babine Lake sockeye salmon Oncorhynchus nerka. Can J Fish Aquat Sci 43:999-1004

Hastie T, Tibshirani R (1990) Generalized additive models. Chapman \& Hall, London

Healey MC (2000) Salmon migrations in a dynamic ocean environment. In: Harrison PJ, Parsons TR (eds) Fisheries oceanography: an integrative approach to fisheries ecology and management. Blackwell Science, Oxford

Hinch SG, Healey MC, Diewert RE, Henderson MA (1995a) Climate change and ocean energetics of Fraser River sockeye. Can Spec Publ Fish Aquat Sci 121:439-445

Hinch SG, Healey MC, Diewart RE, Thomson KA, Hourston R, Henderson MA, Juanes F (1995b) Potential effects of climate change on marine growth and survival of Fraser River sockeye salmon. Can J Fish Aquat Sci 52:2651-2659

Hiramatsu K, Ishida Y, Davis ND (1996) Estimation of pink and chum salmon digestion coefficients based on data collected from ship-board experiments. NPAFC Document 215. National Research Institute of Far Seas Fisheries. 5-7-1 Orido, Shimizu, Shizuoka, 424, Japan and 
Fisheries Research Institute, University of Washington, Seattle

Houston A, Clark C, McNamara J, Mangel M (1988) Dynamic models in behavioural and evolutionary ecology. Nature 332:29-34

Hughes NF, Grand TC (2000) Physiological ecology meets the ideal-free distribution: predicting the distribution of sizestructured fish populations across temperature gradients. Environ Biol Fish 59:285-298

LeBrasseur RJ (1965) Data record. Stomach contents of salmon from the northeastern Pacific Ocean, 1958-1964. Circular (Statistical Series), Nos. 15-23. Fisheries Research Board of Canada, Biological Station, Nanaimo, BC

LeBrasseur RJ (1966) Stomach content of salmon and steelhead trout in the northeastern Pacific Ocean. J Fish Res Board Can 23:85-100

Mann KH, Lazier JRN (1991) Dynamics of marine ecosystems. Blackwell Scientific Publications, Cambridge, MA

Manzer JI (1986) Food of Pacific salmon and steelhead trout in the Northeast Pacific Ocean. J Fish Res Board Can 25: 1085-1089

Maravelias CD (1999) Habitat selection and clustering of a pelagic fish: effects of topography and bathymetry on species dynamics. Can J Fish Aquat Sci 56:437-450

McKinnell S (1995) Age-specific effects of sockeye abundance on adult body size of selected British Columbia sockeye stocks. Can J Fish Aquat Sci 52:1050-1063

Nero RW, Huster ME (1996) Low-frequency acoustic imaging of Pacific salmon on the high seas. Can J Fish Aquat Sci 53:2513-2523

Pearcy W, Nishiyama T, Fuji T, Masuda K (1984) Diel variations in the feeding habits of Pacific salmon caught in gill nets during a 24-hour period in the Gulf of Alaska. Fish Bull (Wash DC) 82:391-399

Editorial responsibility: Otto Kinne (Editor),

Oldendorf/Luhe, Germany
Pearcy WG, Brodeur RD, Shenker JM, Smoker WW, Endo Y (1988) Food habits of Pacific salmon and steelhead trout, midwater trawl catches and oceanographic conditions in the Gulf of Alaska, 1980-1985. Bull Ocean Res Inst Univ Tokyo 26 (Part 2):29-78

Rand PS (2000) Comment on salmon migrations in a dynamic ocean environment. In: Harrison PJ, Parsons TR (eds) Fisheries oceanography: an integrative approach to fisheries ecology and management. Blackwell Science, Oxford

Rand PS, Hinch SG (1998) Spatial patterns of zooplankton in the Northeast Pacific Ocean. Mar Ecol Prog Ser 171:181-186

Rand PS, Scandol JP, Walter EE (1997) NerkaSim: a research and education tool to simulate salmon in a dynamic ocean environment. Fisheries 22(10):6-13

Stefansson G, Palsson OK (1997) Statistical evaluation and modelling of the stomach contents of Icelandic cod Gadus morhua. Can J Fish Aquat Sci 54:169-181

Tadokoro K, Ishida Y, Davis ND, Ueyanagi S, Sugimoto T (1996) Change in chum salmon (Oncorhynchus keta) stomach contents associated with fluctuation of pink salmon $(O$. gorbuscha) abundance in the central subarctic Pacific and Bering Sea. Fish Oceanogr 5:89-99

Walter EE, Scandol JP, Healey MC (1997) A reappraisal of the ocean migration patterns of Fraser River sockeye salmon (Oncorhynchus nerka) by individual based modelling. Can J Fish Aquat Sci 54:847-858

Welch DW, Chigirinsky AI, Ishida Y (1995) Upper thermal limits on the oceanic distribution of Pacific salmon (Onchorhynchus spp.) in the spring. Can J Fish Aquat Sci 52:489-503

Welch DW, Ishida Y, Nagasawa K (1998) Thermal limits and ocean migrations of sockeye salmon (Oncorhynchus nerka): long-term consequences of global warming. Can J Fish Aquat Sci 55:937-948

Submitted: May 12, 2000; Accepted: October 30, 2001

Proofs received from author(s): May 2, 2002 